\title{
Electroencephalographic Sleep in Recently Remitted, Elderly Depressed Patients in Double-Blind Placebo-Maintenance Therapy
}

Jung H. Lee, M.D., Charles F. Reynolds III, M.D., Carolyn C. Hoch, Ph.D., Daniel J. Buysse, M.D., Sati Mazumdar, Ph.D., Charles J. George, B.S., and David J. Kupfer, M.D.

The aim of this double-blind placebo-controlled study mos to assess the effects of clinical state on dactroencephalographic (EEG) sleep measures in elderly petients with recurrent major depression. We hypothesized that rapid-eye movement (REM) latency and delta sleep ratio would remain stable between actively depressed and remitted states (i.e., show state independence), and measures of sleep continuity would improve with remission (i.e., show state dependence). Fiffeen elderly outpatients (mean age 65.3 years) had slap evaluations while ill and after remission, an average of 38 weeks later. All patients were in a double-blind pacebo-maintenance condition at the time of follow-up studies. The major findings were: 1) no significant change in either REM latency or delta sleep ratio; 2) reduction in early morning awakening; and 3) improvement in subjective sleep quality despite the stability of most polysomnographic measures. We conclude that REM latency and delta sleep ratio are stateindependent in patients with late-life depression, and that early morning awakening and sleep quality improve with remission of symptoms. These findings suggest that EEG sleep changes may have significance for understanding the longitudinal course of depression in late life.

[Neuropsychopharmacology 8:143-150, 1993]
XFY WORDS: Electroencephalographic sleep; Depression; Late life; State dependence

Characteristic sleep changes during acute episodes of late-life depression have been well described and include decreased rapid-eye movement (REM) sleep latency (usually under 50 minutes), shift of REM sleep into the furst REM sleep period (often longer than 25

From the Sleep and Chronobiology Center and the Late-Life Depression Prevention Program, Department of Psychiatry (CFR, CCH, DJB, CJG, DJK), University of Pittsburgh School of Medicine, Retsburgh, Pennsylvania; the Department of Biostatistics, Graduate School of Public Health (SM), and Department of Neurology (JHL), Cese Western Reserve University,

Address reprint requests to: Charles F. Reynolds, M.D., Western Ayychiatric Institute and Clinic, Room 1135-E, 3811 O'Hara Street, Ritsburgh, Pennsylvania 15231.

Received February 2, 1992; revised April 17, 1992; accepted April 2. 1992. minutes), diminished delta sleep ratio (ratio of delta wave cpm in the first non-REM (NREM) period to delta wave cpm in the second NREM period: typically less than 1.1), and diminished overall sleep efficiency (typically $75 \%$ or lower), relative to healthy elderly control subjects (Reynolds et al. 1988). Diminution in sleep efficiency often reflects the presence of increased wakefulness throughout the night, but particularly early morning awakening. Electroencephalographic (EEG) sleep changes are more pronounced in elderly depressed, compared to middle-aged and young-adult patients (Gillin et al. 1981; Knowles and MacLean 1990; and Riemann and Berger 1989). Such findings, particularly in the first NREM-REM sleep cycle, have led to specific theoretical models of sleep regulation in major depression (see Reynolds et al. 1987).

In mid-life depressed patients, persistent abnormalities of sleep, such as reduced slow-wave sleep or reduced REMlatency, have been documented following remission of depressive symptoms and discontinuation 
of antidepressant therapy (e.g., Hauri et al. [1974] found persistent reduction in slow-wave sleep, and Rush et al. [1986], Cartwright [1983], and Thase and Simons [1992] reported persistent reduction in REM latency). These findings suggest a trait-like characteristic that may persist regardless of the clinical status of depression and thus differs from the apparent state dependence of other biologic correlates of depression. A longterm follow-up study would be needed to show whether persistent shortening of REM latency is a true trait marker or represents physiologic lag ("scarring") in the recovery of sleep abnormalities in major depressive illness (Cartwright 1983).

Similar questions remain unanswered about the significance of EEG sleep changes in the longitudinal course of depressive illness in late life. The delineation of state-dependent and state-independent (i.e., traitlike) correlates of late-life depression has significant conceptual implications for hypotheses of: personal vulnerability for illness onset, relapse and recurrence, or chronicity; and correlates of clinical severity that may help to better understand the pathophysiology of an episode and hence develop specific treatment interventions.

We have recently presented data on EEG sleep changes during early continuation treatment with nortriptyline (NT) in elderly patients with recurrent major depression, showing that the best single correlates of clinical improvement during NT treatment were prolongation of REM latency and increase of delta sleep ratio (Reynolds et al. 1991). Reduction in REM latency has been proposed as a correlate of relapse or recurrence in both mid-life (Giles et al. 1987) and late-life depression (Reynolds et al. 1989). Similarly, a reduction in delta sleep ratio to 1.1 or less has been found to be a correlate of early recurrence in mid-life depression (Kupfer et al. 1990). These are, therefore, the primary dependent variables of the present study.

This report is a sequel to our earlier study of sleep in early continuation therapy on NT; we now provide data on sleep during early maintenance treatment, af- ter symptoms of depression have remitted and patients have been randomly assigned to maintenance therapy either with NT or placebo. More specifically, this paper focuses on sleep during early maintenance therapy in the group randomized to placebo. In these patients, ongoing effects of NT on sleep measures should be minimized or eliminated (by virtue of NT discontinuation and placebo substitution 4 weeks before followup sleep evaluation), allowing a dissection of statedependent versus state-independent effects of illness.

In summary, the questions addressed by this study are: 1) do EEG sleep measures change from baseline (i.e., patients acutely ill and psychotropic drug-free) to the period of early maintenance therapy (i.e., symptoms remitted, NT withdrawn, and placebo substituted under randomized double-blind conditions); 2 ) which sleep variables are possibly state independent (i.e., traitlike); and 3) which sleep variables are state dependent. We hypothesized that the two primary dependent variables, REM latency and delta sleep ratio, would be state independent (consistent with laboratory data from mid. life samples), but that measures of sleep quality and EEG sleep continuity would be state dependent, showing evidence of improvement with remission of depressive symptoms (consistent with clinical and epidemiologic data).

\section{SUBJECTS AND METHODS}

The 15 outpatients described in Table 1 are participants in an ongoing double-blind placebo-controlled trial of maintenance therapies in late-life depression and were also included as part of a larger sample $(n=30)$ in our earlier study of EEG sleep during early continuation therapy with NT (Reynolds et al. 1991). Inclusion criteria require that patients: be 60 to 80 years of age at admission to protocol; be minimally in their second lifetime episode of major depression (unipolar, nondelusional) as determined by structured interview with the Schedule for Affective Disorders and Schizophrenia, Lifetime

Table 1. Demographic and Clinical Measures ${ }^{a}$

\begin{tabular}{|c|c|c|c|c|c|c|}
\hline & T1 & T3 & Controls & $\begin{array}{c}\text { T1 vs. T3 } \\
\text { (Paired } t \text {-Test) }\end{array}$ & $\begin{array}{l}\text { T1 vs. Controls } \\
\text { (Group } t \text {-test) }\end{array}$ & $\begin{array}{r}\text { T3 vs. Controls } \\
\text { (Group } t \text {-test) }\end{array}$ \\
\hline Night 1 Age & $65.3(4.4)$ & & $65.2(4.3)$ & & & \\
\hline Sex (Males/Females) & $5 / 10$ & & $5 / 10$ & & & \\
\hline Episode Number (Median [Range]) & $3[2-15]$ & & & & & \\
\hline Hamilton (HDRS: 17 item) & $21.9(4.0)$ & $7.2(4.0)$ & $0.6(1.3)$ & $9.24^{b}$ & $19.38^{b}$ & $5.22^{b}$ \\
\hline Global Assessment Scale & $56.8(7.3)$ & $78.7(6.8)$ & $99.2(1.5)$ & $7.93^{b}$ & $-22.07^{b}$ & $-9.01^{b}$ \\
\hline Beck Depression Inventory & $26.6(8.8)$ & $4.1(3.9)$ & $2.4(2.5)$ & $10.47^{b}$ & $10.21^{b}$ & 1.34 \\
\hline Pittsburgh Sleep Quality Index & $10.4(3.8)$ & $6.9(4.4)$ & $3.1(1.3)$ & $3.22^{c}$ & $7.05^{b}$ & $3.80^{b}$ \\
\hline
\end{tabular}

\footnotetext{
${ }^{a}$ Statistical significance is reached at $p=<0.05$.

${ }^{h} p=<0.001$.

$c p=<0.01$.
} 
ression ([SADS-L], Spitzer et al. 1976; Spitzer 1978); bre a rating of 17 or above on the 17-item Hamilton Depression Rating Scale (HDRS) (Hamilton 1960) after 1 14day psychotropic drug-free observation period; nd have a score of 28 or higher on the Folstein MiniMental State test (Folstein et al. 1975) at the end of the 14 day drug-free observation period. The end of the prior episode must have occurred within 2.5 years of the start of the index episode, but with an interval of renission of at least 3 months. An additional inclusion oiterion is that patients' medical illnesses be stable, nonprogressive, and considered to be under optimum medinl management using medications not known to cause depression or changes in sleep. After a physical and nurologic examination and routine laboratory studies complete blood count, electrolytes, liver, kidney, and thyroid functions tests, electrocardiogram, B12 and folate levels, chest $x$-ray, and urine analysis), patients medical data were rated using the Cumulative Illness Rating Scale (Linn et al. 1968) to quantify concurrent medicalburden. We have previously documented reliwle ratings of chronic medical burden in elderly depressed patients (Miller et al. 1992).

Sleep data from a group of 15 age- and sex-equated healthy control subjects are provided for comparison. Data from these control subjects were also included as part of the 30 control subjects' data reported previously (Reynoldset al. 1991). Depression ratings (HDRS, Beck Depression Inventory [BDI]), Global Assessment Scale (GAS) ratings, and sleep quality scores for the control subjects are provided in Table 1.

\section{Treatment of Depression: Acute and Continuation Therapy}

As previously reported (Reynolds et al. 1991), the index episode of depression was treated in open trial using a combination of NT and interpersonal psychotherapy (Klerman et al. 1984), the latter modified for use in elderly patients (Frank et al. in press). To be entered into continuation (stabilization) therapy, patients were required to achieve and maintain for 3 consecutive weeks a HDRS score of 10 or lower, with steady-state plasma NT levels in the range of 50 to 150 $\mathrm{ng} / \mathrm{ml}$. Nortriptyline levels were determined using high-performance liquid chromatography (Foglia et al. 1987). After 16 weeks of continuation treatment (HDRS sores at 10 or below), patients were randomly assigned wa maintenance therapy cell with either NT or placebo. Patients assigned to a placebo condition were gradualy withdrawn from NT during a transition period of 6 weeks under double-blind discontinuation conditions. Sleep studies were then repeated 4 weeks into maintenance therapy (i.e., 4 weeks after discontinuation of NT and substitution of placebo tablets). The mean interval between baseline sleep evaluation and sleep evaluation early in maintenance was 38.4 weeks (SD: 5.9; range: 30.4 to 54.3 weeks). This interval consisted of the period of acute therapy (about 12 weeks on average), continuation therapy (16 weeks), transition to maintenance ( 6 weeks), and 4 weeks of maintenance therapy in a placebo condition.

As noted in Table 1, patients had moderately severe depressive symptoms (HDRS, BDI) and overall functional impairment ([GAS], Endicott et al. 1976) at the time of baseline sleep assessment. Paired $t$-tests showed marked decrease in HDRS and BDI scores from baseline to early maintenance therapy and significant improvement in GAS ratings. Four of 15 patients had subsyndromal depressive symptoms (two with HDRS of 13; and two with scores of 14) at the time of T3 sleep assessment. The remaining 11 patients all had HDRS scores of less than 10 .

\section{Assessment of Sleep}

Laboratory-based polysomnographic evaluation was performed at baseline (designated " $\mathrm{T} 1$ " for convenience) and during early maintenance therapy ("T3"). ("T2" evaluation during early continuation therapy with NT has been reported elsewhere, Reynolds et al. 1991). The scheduling of laboratory studies was determined by each subject's habitual sleep schedule at home, estimated from data in a daily log completed over a 14-day period. On each occasion patients had 3 consecutive nights of polysomnography in the Sleep and Chronobiology Center of Western Psychiatric Institute and Clinic, including monitoring for sleep-disordered breathing, cardiac arrhythmia, and periodic limb movements on the first night of each series. Details of data acquisition and processing, including scoring reliability, have been described elsewhere (Reynolds et al. 1988, and 1991). High- and low-filter frequency settings (Grass model 78D polygraph) for the EEG and electrooculogram were $30 \mathrm{~Hz}$ and $0.3 \mathrm{~Hz}$, respectively. Records were scored in 60-second epochs using the standard criteria specified by Kales and Rechtschaffen (1968). In monthly checks of interrater reliability, we maintain agreement across 15 major sleep variables of $85 \%$ or better (range of variability across raters for REM latency is consistently under $5 \%$ ). In addition to visual scoring of records, automated (period) analyses of EEG slow-wave activity ( 0.5 to $3.0 \mathrm{~Hz}, 75$ to $250 \mathrm{mV}$ ) were also conducted, using methods previously reported by Doman and Kupfer (1988).

Subjective sleep quality was measured using the Pittsburgh Sleep Quality Index (PSQI) (Buysse et al. 1989), administered at the $T 1$ and $T 3$ sleep assessments. The PSQI score quantifies various aspects of subjective sleep quality during the month preceding its administration. Scores of five or lower reliably identify "good" sleepers. 
Primary dependentvariables were REMlatency and delta sleep ratio. Rapid-eye movement latency is measured by the duration of the first NREM sleep period corrected for intervening wakefulness. We also present data on REM latency uncorrected for intervening wakefulness in Table 1, but throughout the text we refer to corrected REM latency, consistent with other publications from our laboratory. Delta sleep ratio, as noted above, is the ratio of delta wave counts per minute in the first NREM period to the second NREM period. In addition to these two primary dependent variables, we examined changes in 11 other secondary measures that are traditionally used by sleep researchers to describe aspects of sleep continuity and sleep architecture. Sleep continuity measures include: 1) total recording period; 2) sleep latency (time in minutes from the start of recording to the first 10 minutes of stage 2 sleep, with no more than two intervening minutes of stage 1 or wakefulness); 3) sleep maintenance (percentage of time spent asleep to total recording period, after correction for sleep latency); and 4) early morning awakening (total wakefulness during the final 2 hours of the recording). The seven measures of sleep architecture include percentages of time asleep in stages 1, 2, slow-wave sleep (i.e., sum of stages 3 and 4), and REM sleep, as well as measures of phasic REM activity counts, REM density (ratio of REM counts to minutes of REM sleep), and duration of first REM period.

\section{Statistical Analyses}

Since the study used a within-subject repeated-measures design, we contrasted the T1 and T3 measures (means of nights 2 and 3 in each series) via paired $t$-tests. As a second test of stability, we calculated Pearson product-moment correlation coefficients (T1 vs. $\mathrm{T} 3$ ) and examined scatterplots of the primary dependent variables. Because we had planned contrasts for testing hypotheses specified a priori and used a relatively small number of dependent variables, we chose not to employ Bonferroni correction. We accepted a $p$ value of less than .05 as our criterion of statistical significance.

Patient values at T1 and T3 were contrasted separately with control values using group $t$-tests. Pearson correlation coefficients were used to examine the relationship between REM latency and delta sleep ratio.

\section{RESULTS}

The two primary dependent variables (REM latency and delta sleep ratio) did not change significantly between $\mathrm{T} 1$ and T3, using paired $t$-tests. The Pearson analysis revealed a significant correlation between $\mathrm{T} 1$ and $\mathrm{T} 3$ values for corrected REM latency $(r=0.64, n=15, p=$ $0.01)$, but not for uncorrected REM latency $(r=0.41$, NS). With respect to delta sleep ratio values, no significant test-retest correlation of $\mathrm{T} 1$ and $\mathrm{T} 3$ values was detected $(r=0.05, \mathrm{NS})$. As shown in the scatterplot, some subjects showed an increase in delta sleep ratio at T3, and others showed a decrease. A test for homogeneity of correlations (to test the null hypothesis of no significant difference between test-retest correlations for REM latency and delta sleep ratio) yielded a chi square of $3.01(p=0.08)$. Thus, REM latency appeared to show a trend toward greater within-subject stability
Figure 1. The mean $( \pm S D)$ REM latency at baseline ( $\mathrm{T} 1=$ depressed, psychotropic drugfree) was 48.9 minutes; and during maintenance, an average of 38 weeks later $(\mathrm{T} 3=$ remitted, on placebo), 53.0 minutes (paired- $t=0.78, n=$ 15, NS). The T1 to T3 test-retest correlation was significant $(r=$ $0.64, n=15, p<0.01$ ).

\section{REM Latcncy: Depressed versus Remitted}

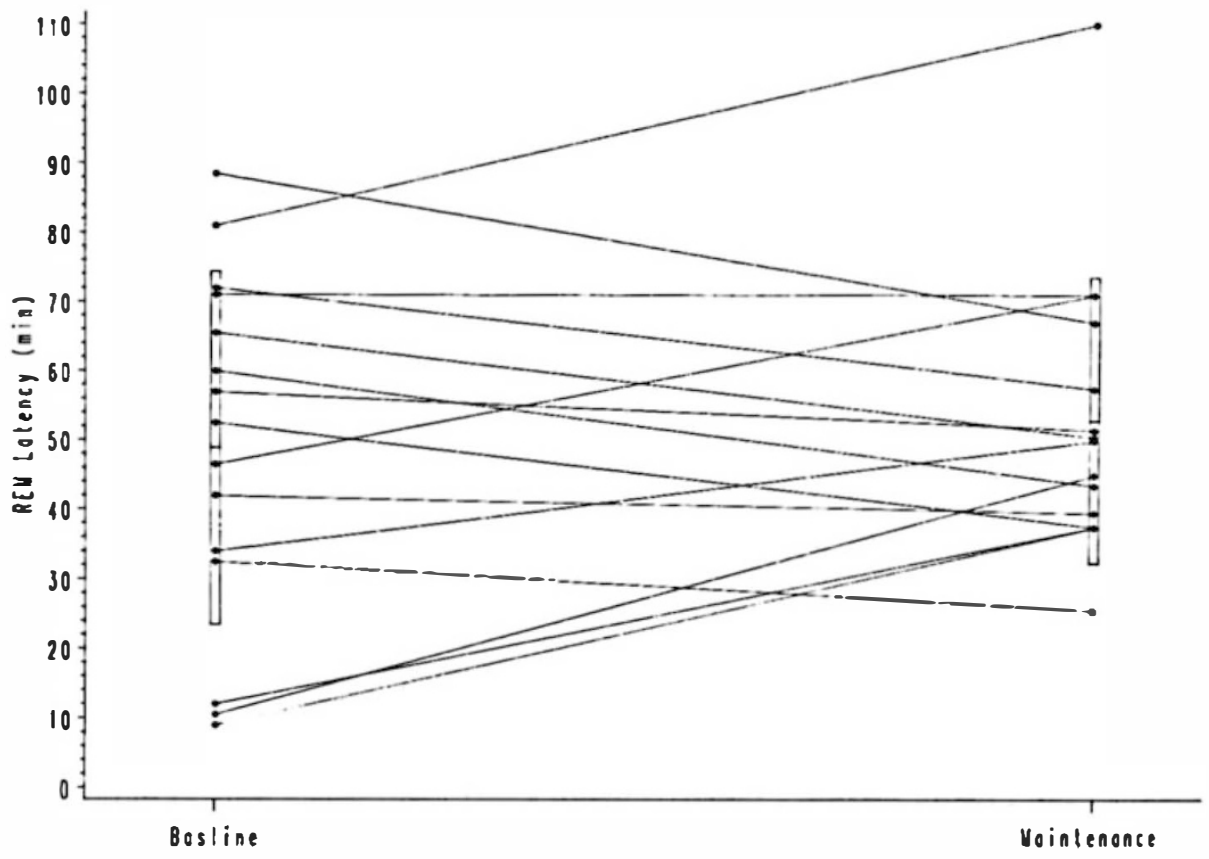


Delta Sleep Ratio: Depressed versus Remitted

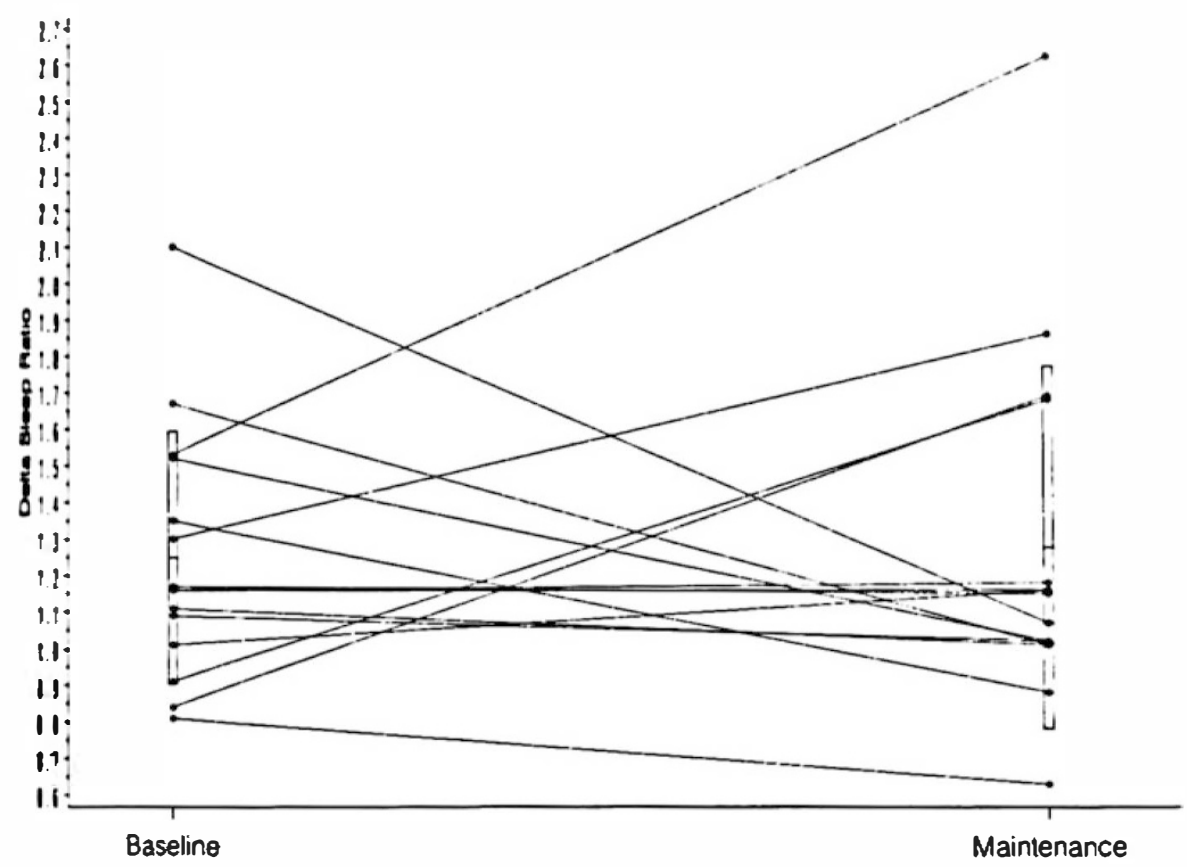

Figure 2. The mean $( \pm S D)$ delta sleep ratio at baseline was 1.2 and during maintenance, 1.3 (paired- $t=0.75, n=15, \mathrm{NS}$ ). The test-retest correlation was not significant $(r=0.05, n=$ $15, \mathrm{NS})$. than did delta sleep ratio. Furthermore, although REM Itency and delta sleep ratio were significantly correated at $\mathrm{T} 1(r=0.74, p=0.002)$, they were not sqnificantly correlated at T3 ( $r=0.18, \mathrm{NS})$, nor were they significantly correlated in control subjects $(r=0.43$, $n=15, p=0.11$ ). In depressed patients, variances were stable at both timepoints for delta sleep ratio $(F=2.06$, $p=0.19)$ and REM latency $(F=1.53, p=0.44)$, argu- ing against a regression to the mean. However, it is notable that three sleep-onset REM periods present at $\mathrm{T} 1$ vanished at $\mathrm{T} 3$.

Only one of eleven secondary sleep measures, early morning awakening, showed a statistically significant change from illness (T1) to early remission on placebo (T3), decreasing from 35.9 (24.2) minutes to 22.4 (15.9) minutes (paired $t=2.18, n=15, p<0.05$ ). The Pear-

Table 2. Sleep Measures

\begin{tabular}{|c|c|c|c|c|c|c|c|}
\hline & \multirow[b]{2}{*}{ T1 } & \multirow[b]{2}{*}{ T3 } & \multirow[b]{2}{*}{ Control } & \multicolumn{2}{|c|}{ T1 vs. T3 } & \multirow{2}{*}{$\begin{array}{l}\text { T1 vs. } \\
\text { Controls } \\
\text { Group-t }\end{array}$} & \multirow{2}{*}{$\begin{array}{l}\text { T3 vs. } \\
\text { Controls } \\
\text { Group-t }\end{array}$} \\
\hline & & & & Paired-t & Pearson-r & & \\
\hline $\begin{array}{l}\text { Skep Continuity: } \\
\text { Total Recording Period (min) } \\
\text { Sleep Latency (min) } \\
\text { Early Morning Awakening } \\
\text { Maintenance (\%) }\end{array}$ & $\begin{array}{c}449.8(35.1) \\
25.1(15.0) \\
35.9(24.2) \\
85.0(8.5)\end{array}$ & $\begin{array}{r}456.4(45.6) \\
24.6(27.4) \\
22.4(15.9) \\
86.8(8.1)\end{array}$ & $\begin{array}{c}465.5(63.8) \\
16.0(7.3) \\
22.0(13.4) \\
88.2(6.9)\end{array}$ & $\begin{array}{l}0.47 \\
0.07 \\
2.18^{a} \\
0.75\end{array}$ & $\begin{array}{l}0.10 \\
0.55^{a} \\
0.34 \\
0.40\end{array}$ & $\begin{array}{c}-0.84 \\
2.11^{a} \\
1.94 \\
-1.15\end{array}$ & $\begin{array}{r}-0.45 \\
1.18 \\
0.07 \\
-0.54\end{array}$ \\
\hline $\begin{array}{l}\text { Steep Architecture (Non REM): } \\
\text { Stage } 1(\%) \\
\text { Stage } 2(\%) \\
\text { Delta }(\%) \\
\text { Delta Sleep Ratio }\end{array}$ & $\begin{array}{r}7.1(5.9) \\
60.8(6.6) \\
6.8(6.4) \\
1.2(0.3)\end{array}$ & $\begin{array}{r}7.0(3.4) \\
64.6(5.6) \\
3.8(3.4) \\
1.3(0.5)\end{array}$ & $\begin{array}{r}6.7(6.9) \\
65.8(7.2) \\
5.2(5.8) \\
1.4(0.4)\end{array}$ & $\begin{array}{l}0.04 \\
1.83 \\
2.03 \\
0.17\end{array}$ & $\begin{array}{l}0.07 \\
0.15 \\
0.48 \\
0.05\end{array}$ & $\begin{array}{r}0.15 \\
-1.97 \\
0.70 \\
-1.02\end{array}$ & $\begin{array}{r}0.14 \\
-0.52 \\
-0.71 \\
-0.67\end{array}$ \\
\hline $\begin{array}{l}\text { REM Sleep: } \\
\text { REM \% } \\
\text { REM Latency (min) } \\
\text { REM Latency With Awake } \\
\text { REM Activity } \\
\text { REM Density } \\
\text { lst REM Period (min) }\end{array}$ & $\begin{aligned} 25.3(7.1) \\
48.9(25.5) \\
51.9(29.1) \\
146.5(79.6) \\
1.6(0.7) \\
26.6(17.3)\end{aligned}$ & $\begin{array}{r}24.5(5.3) \\
53.0(20.6) \\
62.5(27.8) \\
116.8(41.7) \\
1.3(0.4) \\
25.1(10.1)\end{array}$ & $\begin{array}{r}22.3(4.7) \\
61.1(21.6) \\
65.7(26.2) \\
119.2(60.9) \\
1.3(0.5) \\
18.9(8.1)\end{array}$ & $\begin{array}{l}0.58 \\
0.78 \\
1.32 \\
1.94 \\
2.02 \\
0.40\end{array}$ & $\begin{array}{l}0.61^{a} \\
0.64^{b} \\
0.41 \\
0.69^{b} \\
0.66^{b} \\
0.54^{a}\end{array}$ & $\begin{array}{r}1.38 \\
-1.42 \\
-1.36 \\
1.05 \\
1.23 \\
1.57\end{array}$ & $\begin{array}{r}1.19 \\
-1.06 \\
-0.33 \\
-0.13 \\
0.03 \\
1.85\end{array}$ \\
\hline
\end{tabular}

\footnotetext{
$i p<0.05$.
}

$p<0.01$. 
son analysis demonstrated significant test-retest correlations for five of eleven secondary variables: sleep latency, REM percent, phasic REM activity counts, REM density, and first REM period duration (Table 2).

The scatterplots showed two outliers in the measures of T3 sleep (as determined by any valuelying more than two standard deviations from the mean at that timepoint). One patient had an elevated T3 REM latency (110 minutes); a second patient had an elevated T3 delta sleep ratio (2.62). Although both patients had HDRS scores of 14 at the time of T3 sleep, neither has yet had a recurrence of major depression. Removing both patients from the analysis did not affect the results of the $\mathrm{T} 1$ to $\mathrm{T} 3$ comparisons. Thus, the reduction in early morning awakening from $\mathrm{T} 1$ to $\mathrm{T} 3$ was still significant (paired $t=2.32, n=13, p=0.038$ ), and all other sleep measures showed no change over time. Despite the stability of most sleep physiologic measures, improvement in subjective sleep quality was suggested by decreases in PSQI scores from $10.4(3.8)$ at T1 to $6.9(4.4)$ at T3 (paired $t=3.22, n=15, p<0.01$ ).

Significant patient-control group differences in HDRS, GAS, and PSQI scores persisted at T3, consistent with our observation that four of fifteen patients were experiencing subsyndromal symptoms at the T3 sleep assessment. The change in PSQI for males was $-3.4(4.1)$ and for females, $-3.6(4.5)$. These means were not significantly different. With the exception of sleep latency, no significant control-patient differences in any EEG sleep measures were detected at T1 or T3.

\section{DISCUSSION}

To our knowledge, this is the first double-blind placebocontrolled study of EEG sleep in recently remitted elderly depressed patients. The data demonstrate: 1) clinically significant improvement, but not normalization, in sleep quality scores (PSQI) accompanying improvement of depressive symptoms; 2) clinically and statistically significant improvement in the polysomnographic measure of early morning awakening; 3) no significant change in the primary dependent measures of REM latency and delta sleep ratio; 4) no change in 10 of 11 secondary measures of sleep continuity and sleep architecture, with significant test-retest correlations in 6 of 13 variables from T1 to T3; and 5) a general absence of patient-control differences in EEG sleep measures at $\mathrm{T} 1$ and $\mathrm{T} 3$.

Thus, in response to our first question, most EEG sleep measures in late-life depression, with the exception of early morning awakening, appear not to change from illness to early remission on placebo, 4 weeks after discontinuation of NT. In response to our second question, both primary dependent variables, REM latency and delta sleep ratio, are state independent, but there may be more within-subject variability for delta sleep ratio than for REM latency. Finally, in response to our third question, early morning awakening is state dependent, and its decrease accompanies an improve. ment in subjective sleep quality. The general absence of patient-control differences in EEG sleep measures probably reflects limited statistical power. In our 1991 report, with numbers of 30 per cell, we were able to detect patient-control differences in sleep efficiency (76.3 [10.1]\% vs. $84.7[7.3] \%, t=3.68, p=0.0005)$, early morning awakening (40.3 [21.3] minutes vs. 27.0 [20.2] minutes, $t=-2.49, p=0.02)$, REM latency (46.1 [23.2] minutes vs. 59.9 [19.7] minutes, $t=2.48, p=0.02$ ), and REM percent (25.1 [6.5]\% vs. $22.1[4.0] \%, t=-2.13$, $p=0.04)$, but not for delta sleep ratio (1.2 [0.4] vs. 1.4 $[0.5], t=1.70, \mathrm{NS}$ ).

In our earlierreport on EEG sleep in the samegroup of remitted depressed elders during early continuation therapy with NT ("T2"), we observed significant increases in REM latency and delta sleep ratio relative to baseline (T1) values (Reynolds et al. 1991). The REM sleep percent was also significantly decreased at T2 (during early continuation therapy with NT) relative to T1, and sleep maintenance was significantly increased. This pattern of change at $\mathrm{T} 2$ appears to reflect primarily drug effect, since, following gradual discontinuation of NT after random assignment to placebo and with continuing symptomatic remission, most sleep variables were similar at $\mathrm{T} 3$ (early maintenance, remitted, on placebo) and at T1 (baseline, ill, no tablet).

The clinical improvement in sleep quality at T3 ap. pears to be independent of all polysomnographic mea. sures with the possible exception of early morning awakening. This is a credible finding, consistent with Rodin et al. (1989), who reported that complaints of sleep disturbance covaried longitudinally with severity of self-reported depressive symptoms in a random sample of community-residing elders. Respondents reported heightened sleep disturbance with early morning awakening during periods of heightened depres. sive symptoms. Similarly, in studies of healthy elders, we have also noted little correlation between self. reported sleep quality and polysomnographic measures (Buysse et al. 1991).

The current polysomnographic data are consistent with data from middle-aged depressed patients re. studied after remission of depressive symptoms and discontinuation of antidepressant medication (Rushet al. 1986). Although we cannot rule out the possibility of variance related to drug-discontinuation effects, we think that such effects are unlikely because medication was tapered slowly over 4 to 6 weeks and patients were completely off NT for 4 weeks before T3 sleep assess. ment. Moreover, the finding that REM latency does not increase predictably in recently remitted unmedicated elderly outpatients replicates two recent reports from 
our laboratory utilizing cognitive behavior therapy (Thase and Simons 1992) and interpersonal psychother$4 y$ (Buysse et al. 1992), as well as the earlier report by Rush et al. (1986) of remitted patients withdrawn trom pharmacotherapy. Furthermore, in a recently completed investigation of 45 depressed young-adult and middle-aged men (mean age 38.4 years) treated with cognitive behavior therapy, and restudied in the deep laboratory 1 month after remission of depressive gymptoms, we found that the number of nocturnal rousals decreased in remitted patients (relative to partial remitters and nonresponders) (Thase et al. submitdid). Taken together, these findings suggest a disaggrepation of apparently trait-like or state-independent features of depression (i.e., REMlatency and delta sleep ntio) from more reactive and possibly state-dependent measures (i.e., sleep continuity, including early morning awakening).

Our data are in partial agreement with those of Riemann and Berger (1989), who also noted an improvement in parameters of sleep continuity between remitted and depressed states. However, these authors detected a tendency for normalization of REM latency andREM density in remission. Our data suggest a deorease in REM density from illness to remission that might become statistically significant with a larger sample. Also, as noted, three sleep-onset REM periods during illness were no longer present during remission.

The state independence of REM latency and delta sleep ratio suggests the utility of continuing follow-up studies to examine the relationship of sleep to further dinical course.

\section{ACKNOWLEDGMENTS}

This research was supported, in part, by NIMH Grants 37869,

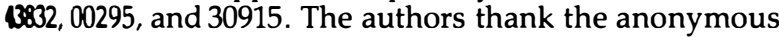
reviewers and the editor of Neuropsychopharmacology for their constructive comments.

\section{REFERENCES}

Beck AT, Ward CH, Mendelson M, Mock J, Erbaugh J (1961): An inventory for measuring depression. Arch Gen Psychiatry 4:61-71

Buysse DJ, Reynolds CF, Monk TH, Berman SR, Kupfer DJ (1989): The Pittsburgh Sleep Quality Index (PSQI): A new instrument for psychiatric research and practice. Psychiatry Res 28:193-213

Buysse DJ, Reynolds CF, Monk TH, Hoch CC, Yeager AL, Kupfer DJ (1991): Quantification of subjective sleep quality in healthy elderly men and women using the Pittsburgh Sleep Quality Index. Sleep 14:331-338

Buysse DJ, Kupfer DJ, FrankE, Monk TH, Ritenour A (1992): EEC sleep studies in depressed patients treated with psy- chotherapy. II. Longitudinal studies at baseline and recovery. Psychiatry Res 40:27-40

Cartwright RD (1983): Rapid eye movement sleep characteristics during and after mood disturbing events. Arch Gen Psychiatry 40:197-201

Doman J, Kupfer DJ (1988): Computer analysis of EEG, EOG, and NPT activity during sleep. Int J Biomed Comput 23:191-200

Endicott J, Spitzer RL, Fleiss JL, Cohen J (1976): The Global Assessment Scale: a procedure for measuring overall severity of psychiatric disturbance. Arch Gen Psychiatry 33:337-341

Foglia JP, Stiller RL, Perel JM (1987): The measure of plasma nortriptyline and its isomeric $10-\mathrm{OH}$ metabolites. Clin Chem 33 (Suppl 6):1024

Folstein MF, Folstein SE, McHugh PR (1975): Mini-Mental State: a practical method for grading the cognitive state of patients for the clinician. J Psychiatr Res 12:189-198

Frank E, Frank N, Cornes C, Imber SD, Morris S, Reynolds CF (1992): Interpersonal psychotherapy in the treatment of late-life depression. In Weissman $M$, Klerman GL (eds), New Applications of Interpersonal Psychotherapy. Washington, DC, American Psychiatric Press (In press)

Giles DE, Jarrett RB, Roffwarg HP, Rush AJ (1987): Reduced rapid eye movement latency: a predictor of recurrence of depression. Neuropsychopharmacology 1:33-39

Gillin JC, Duncan WC, Murphy DL, et al. (1981): Age-related changes in sleep in depressed and normal subjects. Psychiatry Res 4:73-78

Hamilton M (1960): A rating scale for depression. J Neurol Neurosurg Psychiatry 25:56-62

Hauri P, Chernik D, Hawkins D, Mendels S (1974): Sleep of depressed patients in remission. Arch Gen Psychiatry 31:386-391

Klerman GL, Weissman MM, Rounsaville BJ, Chevron ES (1981): Interpersonal Psychotherapy of Depression. New York, Basic Books

Knowles JB, MacLean AW (1990): Age-related changes in sleep in depressed and healthy subjects: a meta-analysis. Neuropsychopharmacology 3:251-259

Kupfer DJ, Frank E, McEachran EA, Grochocinski VJ (1990): Delta sleep ratio: a biological correlate of early recurrence in unipolar affective disorder. Arch Gen Psychiatry 47:1100-1105

Lauer CJ, Riemann D, Wiegand M, Berger M (1991): From early to late adulthood changes in EEG sleep of depressed patients and healthy volunteers. Biol Psychiatry 29:979-993

Linn BS, Linn BW, Gurel L (1968): Cumulative Illness Rating Scale. J Am Geriatr Soc 16:622-626

Miller MD, Paradis CF, Houck PR, Mazumdar Z, Stack JA, Rifai AH, Mulsant B, Reynolds CF (1992): Rating chronic medical illness burden in geropsychiatric practice and research: application of the Cumulative Illness Rating Scale. Psychiatry Res 41:237-248

Rechtschaffen A, Kales A (1968): A Manual of Standardized Terminology, Techniques, and Scoring System for Sleep Stages of Human Subjects. Los Angeles, UCLA Brain Information Service, Brain Research Institute

Reynolds, CF, Gillin JC, Kupfer DJ (1987): Sleep and affec- 
tive disorders. In Meltzer HY (ed), Psychopharmacology: A Third Generation of Progress. New York, Raven Press, pp 647-654

Reynolds CF, Kupfer DJ, Houck PR, Hoch CC, Stack JA, Berman SR, Zimmer B (1988): Reliable discrimination of elderly depressed and demented patients by EEG sleep data. Arch Gen Psychiatry 45:264-268

Reynolds CF, Perel JM, FrankE, Imber SD, Kupfer DJ (1989): Open-trial maintenance nortriptyline in late-life depression: survival analysis and preliminary data on the use of REM latency as a predictor of recurrence. Psychopharmacol Bull 25:129-132

Reynolds CF, Hoch CC, Buysse DJ, George CJ, Houck PR, Mazumdar S, Miller MD, Pollock BG, Rifai AH, Frank E, Cornes C, Morycz RK, Kupfer DJ (1991): Sleep in latelife recurrent depression: changes during early continuation therapy with nortriptyline. Neuropsychopharmacology 5:85-96

Rieman D, Berger M (1989): EEG sleep in depression and in remission and the REM sleep response to the cholinergic agonist RS 86. Neuropsychopharmacology 2:145-152
Rodin J, McAvay G, Timko C (1988): Depressed mood and sleep disturbances in the elderly: a longitudinal study J Gerontol 43:45-52

Rush AJ, Erman MK, Giles DE, Schlesser MA, CarpenterC Vasavada N, Roffwarg HP (1986): Polysomnographic findings in recently drug-free and clinically remitted depressed patients. Arch Gen Psychiatry 43:878-884

Spitzer RL, Endicott J, Robins E (1976): Research diagnostic criteria: rationale and reliability. Arch Gen Psychiatry 35:773-782

Spitzer RL (1978): Schedule for Affective Disorders and Schizophrenia-Lifetime Version (SADS-L). New York New York State Psychiatric Institute

Thase ME, Simons AD (1992): The applied use of psychother apy in the study of the psychobiology of depression. Psy. chother Prac Res 1:72-80

Thase ME, Reynolds CF, Frank E, Jennings JR, Fasiczka AL Garamoni GL, Nofzinger EA, Kupfer DJ: EEG sleep in depressed men before and after treatment with cognitive behavior therapy (submitted) 